\author{
Jean-Michel Jeannin
}

Einleitung

Der Vanillestrauch Vanilla planifolia Andr. (Abb. 1) ist eine immergrüne, rankende Orchidee. Die Wildform kann bis $\mathrm{zu} 25 \mathrm{~m}$ lang werden [1]. Ihre Heimat ist das tropische Amerika, vor allem Mexiko [1]. Die weissen oder hellgrünen Blüten sind zwar unauffällig, weisen aber einen besonderen Bau auf: Die Staubblätter, der Stempel und die Narbe sind zu einer Säule (Gynostemium) verwachsen [2]. Die verblühten Blüten fallen vom Fruchtknoten $a b$, der sich zur Kapselfrucht («Schote») mit den bohnenartigen Samen weiterentwickelt. Die 12-35 cm lange und 5-9 mm dicke Frucht ist dunkelbraun bis schwarz. Das bräunlich-schwarze Fruchtfleisch birgt die zahlreichen kleinen Samen. Sowohl die Droge als auch eine Tinktur sind im «National Formulary» der USA monografiert [3].

\section{Verwendung}

Der Vanillestrauch ist die einzige Orchidee, deren Früchte vom Menschen gegessen werden. Geerntet werden die ausgewachsenen, aber noch grünen Früchte, aus denen das Gewürz in unterschiedlichen Verfahren hergestellt wird, die aber immer eine Fermentation enthalten $[1,4]$. Die Qualität eines Vanillegewürzes wird mehr vom Aroma als vom Vanillingehalt bestimmt [1].

\title{
Exotische Heilpflanzen (10)
}

\author{
Vanilla planifolia (Andr.) (Orchidaceae)
}

\section{Traditionelle Verwendung}

Die spanischen Eroberer berichten vom Gebrauch der Vanille bei Bluthusten und Syphilis. In Mittelamerika wurde die Vanille als Aphrodisiakum verwendet. Im 18. und 19. Jahrhundert wurde die Vanille in Europa offizinell und war zur Behandlung von Fieber, Melancholie und Hysterie indiziert. In der amerikanischen Pharmakopöe wurde die Vanille bis 1916 zur Behandlung von Magenbeschwerden und Hysterie sowie als Stimulans empfohlen [4].

\section{Phytochemie}

Die Vanillefrüchte enthalten 1,3-3,0\% Vanillin, daneben in viel niedrigeren Konzentrationen Parahydroxybenzaldehyd, Essigsäure, Isobuttersäure, Capronsäure, Eugenol, Furfural, Parahydroxybenzylmethylether, Vanillylethylether, Anisylethylether und Acetaldehyd. Weitere Inhaltsstoffe sind Harze, Zucker und Öle.

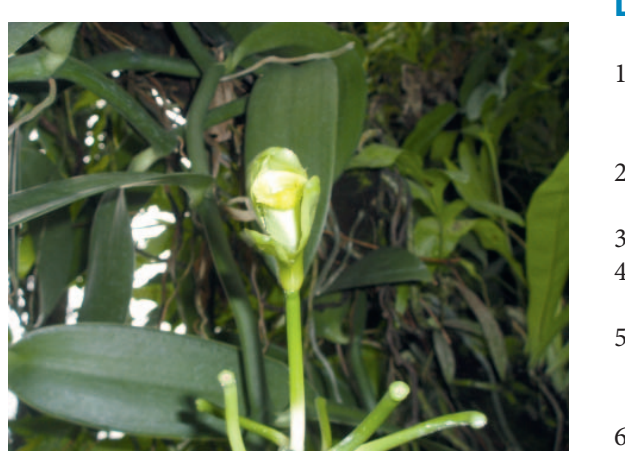

Abb. 1. Sich öffnende Blüte und Fruchtknoten von Vanilla planifolia. Basel, Tropenhaus des Botanischen Gartens, 2011.

\section{Aktuelle Forschung}

In einer In-vitro-Studie zeigte ein Vanille-Extrakt das Potenzial, Bakterien davon abzuhalten, pathogen $\mathrm{zu}$ werden. Die Wirkung wurde durch eine Hemmung des "Quorum Sensing» vermittelt, einem biochemischen Mechanismus, der das pathogene Verhalten von Bakterien induziert. Die Autoren vermuten, dass die Wirkung von einer neuen Inhaltsstoffklasse vermittelt wird [5]. Ein natürlicher alkoholischer Vanille-Extrakt mit 17\% Polyphenolen entfaltete eine antioxidative Wirkung, die zur Konservierung von Lebensmitteln von Interesse sein könnte [6]. Die Untersuchungen mit Vanille als Einzelsubstanz zeigen zwar interessante Ergebnisse, gehören aber streng genommen nicht mehr zur Phytotherapie. Diese Betrachtung wird durch zwei Studien $[5,6]$ illustriert, deren Ergebnisse durch eine Reihe von Substanzen bewirkt wurden.

\section{Literatur}

1 Leung AY, Forster S: Encyclopedia of Common Natural Ingredients, ed 2. New York, John Wiley \& Sons, 1996.

2 Gynostemium. de.wikipedia.org/wiki/ Gynostemium.

3 Vanilla. USP 29/NF 24

4 Bythrow JD: Vanilla as a medicinal plant. Semin Integr Med 2005;3:129-131.

5 Cho $\mathrm{JH}$, et al: Inhibition of bacterial quorum sensing by vanilla extract. Lett Appl Microbiol 2006;42:637-641.

6 Shyanala BN, et al: Studies on the antioxidant activities of natural vanilla extract and its constituent compounds through in vitro models. J Agric Food Chem 2007;55:77387743 .

\section{KARGER}

Fax +497614520714 Information@Karger.de www.karger.com (c) 2011 S. Karger GmbH, Freiburg
Dipl. med. biol. Jean-Michel Jeannin Holeestrasse 43, 4054 Basel, Schweiz

Tel. +41 61-4215991, Fax - 4230313

jmjeannin@dataworks.ch 